\title{
METODOLOGIAS ATIVAS E AS PREFERÊNCIAS DE APRENDIZADO DOS ALUNOS DO ENSINO MÉDIO
}

\author{
Vinícius Barros Rodrigues 12 \\ ${ }^{1}$ Laboratório de Incêndios Florestais e Conservação da Natureza, Universidade \\ Federal de Viçosa, Viçosa - MG \\ ${ }^{2}$ Colégio Nossa Senhora do Carmo, Viçosa - MG \\ viniciusbrbio@gmail.com
}

Resumo. O objetivo deste trabalho foi investigar a percepção de alunos do Ensino Médio frente a diferentes abordagens e técnicas de ensino-aprendizagem, priorizando a construção do conhecimento de forma ativa pelos alunos; bem como avaliar a satisfação e progressão dessa construção junto aos alunos através da proposição de feedback. Concluímos que as metodologias utilizando vídeos, práticas de laboratório, palestras, trabalhos em duplas e "300" foram muito bem recebidas e avaliadas pelos estudantes, mas ressaltamos que mesclar atividades ativas com metodologias passivas, que traduzem maior segurança na interiorização do conteúdo como ideal para a prática docente, uma vez que uma turma apresenta um grupo diversificado de indivíduos com distintas necessidades educacionais.

Palavras-chave: didática; feedback; pesquisa; ciências; educação

\section{INTRODUÇÃO}

O processo de ensino-aprendizagem em sala de aula ainda é pautado, com pouquíssimas exceções, por um sistema passivo em que todas as disciplinas se diferem entre si apenas no conteúdo apresentado aos estudantes (SASSERON, 2018). As aulas são predominantemente expositivas, seguidas de exercícios de fixação, sejam eles elaborados pelo professor ou retirados do livro didático.

A educação contemporânea busca romper com essa passividade dos discentes de diferentes maneiras, seja desafiando-os com problemas reais ou explorando novas tecnologias (MORÁN, 2015). Exemplos de recursos tecnológicos incluem dispositivos eletrônicos, como tablets e computadores, softwares, jogos, aplicativos, vídeos e ambientes virtuais. A utilização destas tecnologias, principalmente das novidades do mercado, como novos aplicativos e ferramentas, podem auxiliar na preparação do jovem para o futuro profissional e é, inclusive, um dos grandes desafios da educação (MATTAR, 2010). A incorporação tecnológica nas práticas pedagógicas busca tornar o processo educacional mais interessante para os estudantes, uma vez que grande parte destas tecnologias já fazem parte do cotidiano dos mesmos, direta ou indiretamente. E essa aproximação com o cotidiano do aluno é cada vez mais 
necessária para e escola avançar em sua missão (SILVA; SALES, 2015; MORÁN, 2018).

O uso de tecnologias em sala de aula, entretanto, não é a única forma de romper com a passividade dos alunos. Metodologias que prezem pelo papel ativo dos estudantes nem sempre envolvem o uso de tecnologias e são cada mais centrais para o sucesso educacional (SALOMON; PERKINS, 1989).

Nesse contexto, as metodologias ativas priorizam um maior envolvimento e engajamento do discente, despertando sua curiosidade e a sua interação com a aula (BERBEL, 2011). São metodologias que, dentre outros, utilizam muito da problematização na estratégia de ensino-aprendizagem (MITRE et al., 2008). Diante do problema proposto pelo professor, o discente pode ressignificar suas descobertas e aumentar sua curiosidade, uma vez que ele examina, relaciona e reflete sobre o tema proposto em aula.

Este contexto ativo também depende do papel do professor como o facilitador do processo de ensino-aprendizagem, estimulando-os a reflexão sobre os assuntos e problemas propostos (SEMIM et al., 2009). Esse comportamento facilitador do professor incluiu buscar boa relação e comunicação com os alunos (SEMIM et al., 2009; SANTEIRO et al., 2004), e também um preparo adequado das aulas (SANTEIRO et al., 2004), com objetivos e metodologias expostas claramente para os alunos.

Um processo bem estruturado e efetivo de aprendizado inclui testar e obter feedback (SHEERENS; BOSKER, 1997). A comunicação direta e o feedback dos alunos sobre o que acontece em sala de aula é extremante importante no processo ensinoaprendizagem (HATTIE, 2009; FELDER; BRENT, 2016). Segundo Hattie (2009) feedback não é apenas do professor para o aluno, mas também do aluno para o professor. Isto inclui escutar e respeitar as opiniões dos alunos, com discussões claras sobre "o quê" e o "porquê" de aquilo ser feito em sala de aula. O processo de feedback deve ser contínuo para que adaptações ocorram ao longo do processo. Escutá-los e alterar o curso das aulas não é premiar e ceder às pressões, mas buscar o interesse e participação dos alunos, colocando-os no centro do processo ensino-aprendizagem. 
Assim, o objetivo deste estudo foi avaliar a opinião dos alunos do primeiro ano do Ensino Médio, como parte do processo contínuo de feedback, frente às diferentes metodologias ativas utilizadas no processo de ensino-aprendizagem (SEMIM et al., 2009) na disciplina de Biologia.

\section{Metodologia}

\section{A escola e coleta de dados}

As metodologias de ensino foram utilizadas na disciplina de Biologia, em duas turmas do primeiro ano do Ensino Médio, no Colégio Nossa Senhora do Carmo, na cidade de Viçosa - Minas Gerais, Brasil. As turmas tiveram cinco aulas semanais da matéria de 50 minutos cada aula. Foram utilizadas diferentes metodologias no processo ensino-aprendizagem (descritas abaixo) ao longo do ano letivo de 2019.

No final do $4^{\mathrm{o}}$ bimestre foi distribuído um formulário para a realização da pesquisa de opinião dos alunos. Os discentes já estavam familiarizados com os nomes e objetivos de cada uma das atividades desenvolvidas ao longo do ano. $\mathrm{O}$ formulário (Figura 1) era composto de duas colunas: (i) nomes da metodologia e descrição das atividades desenvolvidas, e (ii) um campo para o preenchimento da nota referente à metodologia, variando de 0 (zero) até 5 (cinco). 
Aulas no quadro 00000

Aulas com slides 00000

Aulas práticas/laboratório 00000

Vídeos 00000

Podcasts 00000

Atividades em duplas em sala 00000

Apresentações dos alunos 00000

Produção de vídeo/podcast 00000

Flashcards 00000

Linhas do tempo 00000

Quadros sinópticos 00000

Mapas mentais 00000

Discussões em grupo 00000

30000000

Palestras 00000

Atividades do livro 00000

Atividades/leituras para casa 00000

Bookquest 00000

Figura 1: Modelo de ficha utilizado para a avaliação das metodologias.

\section{Técnicas utilizadas}

Ao longo do ano letivo foram utilizadas diferentes metodologias de ensinoaprendizagem, entre metodologias passivas e ativas. As metodologias ativas foram realizadas com base nas propostas de Camargo e Daros (2018), Harmin e Toth (2006), Ward et al. (2009) e Fragelli (2019): (1) Vídeos e animações exibidos em sala de aula, com um auxílio de um data-show, exemplificando os conteúdos; (2) Aulas práticas de laboratório, onde os alunos se deparavam com o método científico e a instrumentação laboratorial; (3) Palestras de convidados sobre um tema visto em sala de aula e aplicado em um contexto real; (4) Atividades em duplas buscando a interação entre os alunos para a resolução de problemas; (5) "Método 300" para estudo em grupo das provas bimestrais (ver Fragelli, 2019); (6) Aulas expositivas com o auxílio de slides; (7) Discussões em grupo sobre um determinado problema; (8) Criação de mapas mentais ao final dos capítulos como forma de roteiro para estudo;

(9) Aulas expositivas ministradas pelo professor utilizando apenas o quadro-negro; (10) Criação de quadros sinópticos ao final dos capítulos como forma de resumo para estudo, (11) Confecção de flashcards da matéria para auxiliar na memorização de 
alguns termos e processos, (12) Produções audiovisuais de situações-problema, como a confecção de vídeos e podcasts; (13) Apresentações orais e expositivas dos alunos para a turma; (14) Atividades individuais utilizando o livro didático; (15) Confecção de linhas do tempo do conteúdo estudado; (16) Escutarem podcasts, em casa, sobre assuntos relacionados com a matéria e responderem algumas perguntas, (16) Bookquests para a realização de atividades e pesquisas em sala de aula e (17) Atividades do livro didático para os alunos resolverem em casa.

\section{Análise estatística}

Os dados coletados foram tabulados e analisados no programa R ( R CORE TEAM, 2019). Para a análise, foi utilizado Modelo Linear Generalizado (GLM), sob distribuição Gaussiana (CRAWLEY, 2007). A variável explicativa do modelo foi "Atividade" e a variável resposta foi "Nota", que correspondeu à nota dada pelos alunos. As diferenças entre as atividades foram acessadas utilizando análise de contraste, como descrito por Crawley (2007).

\section{Resultados e discussão}

Participaram da pesquisa 45 alunos do primeiro ano do Ensino Médio. A nota média das atividades avaliada pelos estudantes foi 3,47. A atividade com maior nota foi "Vídeos" (4,6) e a menor foi "Para casa" (2,2) (Figura 2). A análise de contraste dividiu as metodologias em três grupos: as atividades "Vídeos", "Práticas e laboratório", "Palestras", "Duplas", "300" e "Slides" foram consideradas estatisticamente iguais ( $p>0,05)$; o segundo grupo foi composto por "Discussões", "Mapas mentais", "Quadro", "Quadros sinópticos", "Flashcards", "Produções audiovisuais" e "Apresentações" ( $>>0,05)$; o terceiro grupo foi formado por "Atividades no livro", "Linhas do tempo", "Podcasts", "Bookquests" e "Para casa" $(p>0,05)$. Não houve diferença entre as duas turmas $(p=0,36)$. 


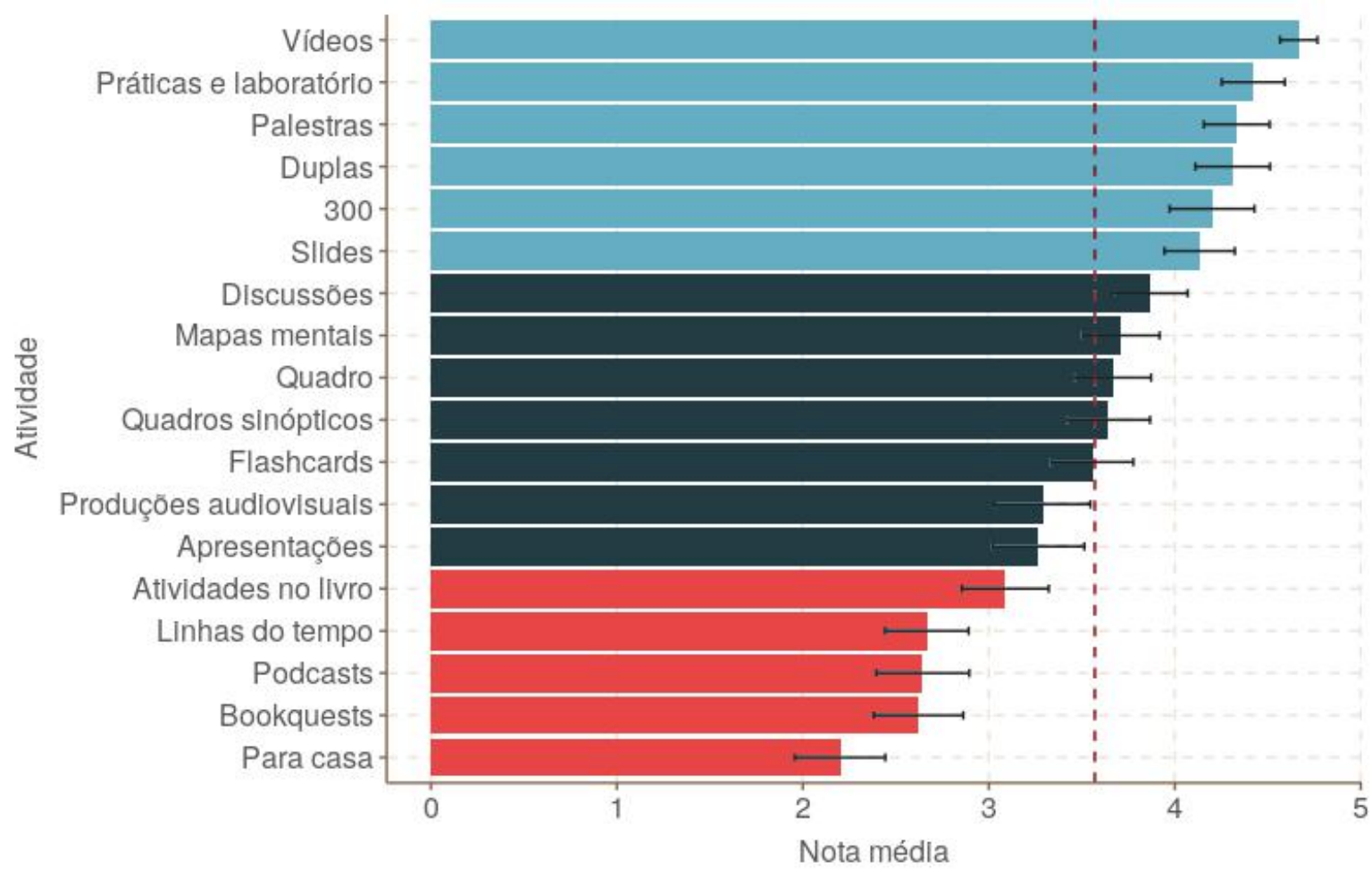

Figura 2: Resultado da votação dos alunos por atividade. Atividades com barras da mesma cor não apresentaram diferença estatística. A linha pontilhada indica a nota média das atividades.

A grande aceitação por vídeos e animações em sala de aula reforça a importância do uso de Tecnologias Digitais de Informação e Comunicação (TDIC) no processo de ensino-aprendizagem. Autores como Castro et al. (2011), Silva et al. (2012) e Silva et al. (2017) já destacaram que a TDIC se aproxima da realidade dos alunos, imersos em um contexto digital, com a linguagem verbal e visual característica das novas tecnologias. As animações utilizadas em sala de aula, todas disponíveis no YouTube, despertam a atenção, emoção e curiosidade nos alunos em sala de aula (Carvalho; Gonçalves, 2000).

Neste contexto das TDIC, podemos incluir também os slides e o uso do datashow que, apesar de possuírem uma característica passiva em relação aos alunos, os alunos apresentaram uma nota acima do esperado. Em feedbacks informais, os alunos disseram que os slides podem ajudar na organização de conteúdos extensos, principalmente em aulas de revisão. As linguagens audiovisuais, no geral, se interagem e podem contribuir com múltiplas percepções de um mesmo tema, impactando diferentes alunos (MORAN, 2018). 
Aulas práticas e de laboratório sempre apresentaram elevada aceitação por parte dos alunos. Estas aulas despertam a curiosidade, dinamizam o ensino e elucidam os fenômenos teóricos (GIORDAN, 1999; SANTOS et. al, 2018). Além disso, estas aulas possuem uma dinâmica própria, fomentando a discussão e participação dos alunos (SASSERON, 2018; VALENGA et al. 2019). Embora as aulas práticas sejam mais relacionadas pelos alunos como uma aula para manipular materiais e realizar experiências (BARTZIK; ZANDER, 2016), estas podem ser muito mais proveitosas se aplicadas adequadamente. Isto é, a aula de laboratório deve ter um objetivo pedagógico além da simples utilização do ambiente e dos utensílios pelos alunos. Além do contato com os materiais e experiências, durante as aulas práticas, os alunos podem experimentar um pouco do método científico utilizado pelos pesquisadores que outrora estudaram um dado fenômeno, sistema ou organismo, contribuindo para o desenvolvimento do pensamento hipotético-dedutivo (PILETTI, 1988).

No ranking de preferências, os podcasts foram a exceção dentro das TDIC. Apesar de ser uma mídia recente e consumida por alguns alunos, essa metodologia não foi bem avaliada para o processo de ensino-aprendizagem. Os podcasts talvez sejam vistos, ainda, como algo meramente ligado ao entretenimento ou pouco interativo. Nossa hipótese é que, com o passar do tempo e a popularização dessa mídia entre os mais jovens, ocorra uma aceitação melhor na sua utilização em processos de estudos, como aconteceu com o YouTube. O YouTube e os vídeos, por sua já possuem grande impacto causado nos métodos de ensino (BURGESS; GREEN, 2009). Autores como Junges e Gatti (2019), inclusive, já mostraram que os alunos utilizam o YouTube para estudar em casa. Assim, desas mídias e plataformas em sala de aula, em momentos específicos e bem inseridos no processo educacional, podem trazer respostas positivas.

Contrário às nossas expectativas, aulas expositivas como o quadro-negro foram melhor avaliadas. Isso pode ter acontecido devido ao contexto de dinamização das aulas, com diferentes metodologias e abordagens, o que deixou as aulas expositivas menos repetitivas. Isto é, aulas puramente expositivas no quadro-negro 
eram utilizadas em poucas aulas e sempre seguidas de alguma atividade ativa. Nesse contexto, a utilização do quadro-negro não passou por um processo de desgaste frente ao interesse dos alunos. Como hipótese alternativa, Kember e Wong (2000) mostraram que muitos alunos ainda são passivos em sala de aula, então uma nota razoavelmente boa frente a este método pode ter sido influenciada por esses alunos. O quadro-negro é uma figura central do mobiliário escolar e sua utilização ainda está muito atrelada ao processo de ensino-aprendizagem (BASTOS, 2005). Apesar das mudanças tecnológicas, o quadro-negro ainda é um importante recurso audiovisual e, mais do que um local para colocar o conteúdo, o quadro auxilia na organização do conteúdo em sala de aula. De posse do conteúdo organizado no quadro-negro pelo professor, alguns alunos sentem-se mais seguros para estudar e revisar o conteúdo fora do ambiente escolar.

Por fim, o método “300” também foi muito bem-aceito pelos alunos. Esta técnica têm sido bem e apresentado bons resultados comparativos (FRAGELLI, 2015; FRAGELLI; OLIVEIRA, 2017). A técnica busca a colaboração entre os alunos, através da formação de grupos de estudos, mesclando alunos com bons rendimentos (ajudantes) com aqueles com rendimento considerado insatisfatório (ajudados). Os ajudados poderão fazer uma nova avaliação do conteúdo. Os ajudantes, por sua vez, não podem refazer a avaliação, mas podem melhorar suas notas iniciais de acordo com a melhora dos ajudados.

As metodologias utilizadas no ensino tradicional, como atividades para casa, atividades no livro didático, mesmo quando utilizadas na forma de bookquests, tiveram baixas avaliações. Como mencionado anteriormente, os estudantes estão em um outro contexto tecnológico e a utilização do livro remete a algo passivo, desinteressante e, talvez, ultrapassado.

\section{Agradecimentos}

Verônica Saraiva Fialho pela revisão e sugestões no texto. Ao Colégio Nossa Senhora do Carmo, Viçosa - MG, pela motivação e por fazer desta parceria um instrumento de reflexão nas práticas educacionais, mas, sobretudo, pelo apoio concedido. 


\section{Referências}

BARTZIK, F.; ZANDER, L. D. A Importância Das Aulas Práticas De Ciências No Ensino Fundamental. Revista @rquivo Brasileiro de Educação, v.4, n. 8, 2016.

BERBEL, N. A. N. As metodologias ativas e a promoção da autonomia de estudantes. Semina: Ciências Sociais e Humanas, v. 32, n. 1, p. 25-40, 2011.

BURGESS, J.;GREEN, J. YouTube e a Revolução Digital: como o maior fenômeno da cultura participativa transformou a mídia e a sociedade. São Paulo: Aleph, 2009.

CAMARGO, F.; DAROS, T. A sala de aula inovadora: estratégias pedagógicas para formentar o aprendizado ativo. Porto Alegre: Penso, 2018.

CARVALHO, A. M. P. \& GONÇALVES, M. E. R. Formação continuada de professores: o vídeo como tecnologia facilitadora da reflexão. Cadernos de Pesquisa, n. 111, p. 71-94, 2000.

CASTRO, B. J.; FRASSON, P. C.; SACHS, L. G.; TAGLIATELA, F. P.; LEVIN, T. G. As TIC e o lúdico no Ensino de Química: potencialidades de um jogo educacional virtual. In: CONGRESSO INTERNACIONAL DE EDUCAÇÃO, 3., 2011, Ponta Grossa. Anais..., Ponta Grossa, 2011.

CRAWLEY, M. L. The R Book. John Wiley \& Sons, 2007.

FELDER, R. M.; BRENT, R. Teaching and learning stem - a practical guide. JosseyBass, 2016.

FRAGELLI, R. Método trezentos: Aprendizagem ativa e colaborativa, para além do conteúdo. Penso Editora, 2019.

FRAGELLI, R. Trezentos: aprendizagem ativa e colaborativa como uma alternativa ao problema da ansiedade em provas. Revista Eletrônica Gestão \& Saúde, n. 6, v. 2, p. $860-72,2015$.

FRAGELLI, R.; OLIVERIA, T. B. Trezentos: a dimensão humana do método. Educar em Revista, n.63, p.253-265, 2017.

GIORDAN, M. O papel da experimentação no ensino de ciências. Química Nova na Escola, n. 10, p. 43-49, 1999.

HARMIN, M.; TOTH, M. Inspiring active learning: a complete handbook for today's teachers. Virginia: Association for Supervision and Curriculum Development Alexandria, 2006. 
HATTIE, J. A. C. Visible Learning A synthesis of over 800 meta-analyses relating to achievement. Routledge, 2009.

JUNGES, D. L. V., GATTI, A. Estudando por vídeos: o Youtube como ferramenta de aprendizagem. Informática na Educação: Teoria \& Prática, v.22, n.2, 2019.

KEMBER, D., \& WONG, A. Implications for evaluation from a study of students' perceptions of good and poor teaching. Higher Education, n.40, p.69-97, 2000.

MATTAR, J. Games em educação: como os nativos digitais aprendem. São Paulo: Person Prentice Hall, 2010.

MITRE, S. M.; SIQUEIRA-BATISTA, R.; GIRARDI-DE-MENDONÇA, J. M.; MORAISPINTO, N. M. D.; MEIRELlES, C. D. A. B.; PINTO-PORTO, C.; MOREIRA, T.; HOFFMANN, L. M. A. Metodologias ativas de ensino-aprendizagem na formação profissional em saúde: debates atuais. Ciência \& Saúde Coletiva, v.13, p.2133-2144, 2008.

MORAN, J. M. Desafios da televisão e o vídeo na escola. Disponível em $<$ http://www.eca.usp.br/prof/moran/site/textos/tecnologias eduacacao/desafio.pdf $>$.

Acesso em Dezembro de 2018.

MORÁN, José. Mudando a educação com metodologias ativas. Coleção mídias contemporâneas. Convergências midiáticas, educação e cidadania: aproximações jovens, v. 2, n. 1, p. 15-33, 2015.

PERKINS, D. N.; SALOMON, G. Are cognitive skills context-bound?. Educational researcher, v. 18, n. 1, p. 16-25, 1989.

PILETTI, C. Didática especial. 6.ed. São Paulo: Ática S.A, 1988.

R CORE TEAM. R: A language and environment for statistical computing. $R$ Foundation for Statistical Computing, Vienna, Austria. Disponível em: https://www.R-project.org/.

SANTEIRO, T. V.; SANTEIRO, F. R. M.; ANDRADE, I. E. Professor facilitador e inibidor da criatividade segundo universitários. Psicologia em Estudo, v. 9, n. 1, p. 95-102, 2004.

SANTOS, P. M. L.; SANTOS, F. L.; LIRA, L. M. A.; JÚNIOR, W. J. T.; LIMA, T. C. EXPERIMENTOS DE BAIXO CUSTO PARA AS AULAS NO LABORATÓRIO DE CIÊNCIAS DA ESCOLA: UMA OFICINA PARA PROFESSORES. Revista de Educação, Ciências e Matemática, v.8, n.3, p. 141-150, 2018. 
SASSERON, L. H. Ensino de Ciências por Investigação e o Desenvolvimento de Práticas: Uma Mirada para a Base Nacional Comum Curricular. Revista Brasileira De Pesquisa Em Educação Em Ciências, N.8, V.3, P.1061-1085, 2018.

SCHEERENS, J.; BOSKER, R. J. The foundations of educational effectiveness. Oxford: Pergamon Press, 1997.

SEMIM, G. M.; SOUZA, M. C. B. M.; CORRÊA, A. K. Professor como facilitador do processo ensino-aprendizagem: visão do estudante de enfermagem. Revista Gaúcha de Enfermagem, N.30, V.3, P.484-91, 2009.

SILVA, J. L.; SILVA, D. A.; MARTINI, C.; DOMINGOS, D. C. A.; LEAL, P. G.; BENEDETTI FILHO, E.; FIORUCCI, A. R. A utilização de vídeos didáticos nas aulas de química. Química Nova na Escola, v.34, n.4, p.189-200, 2012.

SILVA, M. P. O.; SALES, S. R.. O fenômeno cultural do youtube no percurso educacional da juventude ciborgue. In: SEMINÁRIO BRASILEIRO DE ESTUDOS CULTURAIS EM EDUCAÇÃO, 6., 2015, Canoas. Atas..., Canoas, 2015.

SILVA, M. J.; PEREIRA, M. V.; ARROIO, A. O papel do youtube no ensino de ciências para estudantes do ensino médio. Revista de Educação, Ciências e Matemática, v.7 n.2, p.35-55, 2017.

SILVA, M. S.; ZOTTI, K. S.; REHFELDT, M. J. H.; MARCHI, M. I. O uso de mídias digitais, associados ao ambiente virtual de ensino e de aprendizagem, no ensino de química: explorando a radioatividade por meio da educação a distância. Revista Brasileira de Ensino de Ciência e Tecnologia, v. 12, n. 2, 2019.

SILVA, J. B.; SALES, G. L.; LEITE, E. A. M.; PONTELLO, L. S. Mudança Conceitual em Óptica Geométrica Facilitada Pelo Uso de TDIC. In: WORKSHOP DE INFORMÁTICA NA ESCOLA, 21, 2015, Maceió. Anais... Porto Alegre: SBC, 2015, p.1-17. Disponível em: < http://www.br-ie.org/pub/index.php/wie/article/view/5060>. Acesso em: Dezembro de 2018.

VALENGA, F.; RAIMONDI, A.; COLOMBO, K.; BORDIN, K. Uso de aprendizagem baseada em projetos com apoio de outras metodologias ativas para promover aprendizagem ativa no ensino de biotecnologia. Revista Brasileira de Ensino de Ciência e Tecnologia, v. 12, n. 2, p. 148-163, 2019.

WARD, H., RODEN, J., HEWLETT, C., \& FOREMAN, J. Ensino de ciências. Artmed Editora, 2009. 